\title{
The Juvenile Form of Niemann-Pick Disease
}

\author{
R. M. NORMAN, R. M. FORRESTER, and A. H. TINGEY \\ From the Burden Neuropathological Laboratory, Frenchay, Bristol, \\ and the Royal Albert Edward Infirmary, Wigan
}

\begin{abstract}
A new chapter in the history of Niemann-Pick disease opened when Crocker and Farber (1958) published their account of 18 patients and showed how wide the range of variation in the clinical features might be. $U p$ to this time, with the exception of rare adult cases, attention had been confined to the classical infantile form of the disease which presents an almost stereotyped picture of a generalized lipidosis characterized chemically by a large accumulation of sphingomyelin and a moderate excess of cholesterol in the brain and visceral organs. Only one of Crocker and Farber's patients conformed to this type. Although in the majority the first signs of the disease had appeared in infancy, neurological involvement was often delayed, and in several patients life was prolonged into later childhood or adolescence. In all their cases the diagnosis had been confirmed by finding Niemann-Pick foam cells in biopsy specimens or after necropsy. The most striking difference from the infantile form was seen in the chemical findings which were available in some of the cases (Crocker, 1961). The sphingomyelin content of the brain and individual organs varied considerably in amount from case to case and did not necessarily show an absolute increase over normal. An excess of cholesterol appeared to be a more constant anomaly.

The case we are reporting is an example of this 'lower-tissue-lipid' form of Niemann-Pick disease occurring in a child who died at the age of 13 years. The condition gave rise to diagnostic difficulties, because clinically there was no hepatosplenomegaly, and the presenting neurological signs suggested cerebellar disease.
\end{abstract}

\section{Case Report}

K.C. was the third child in her family. There are two older brothers and one younger sister who are normal. She was born on January 11, 1952, after a precipitate labour. The neonatal period was uneventful. She first came to notice in November 1956, when she had an obscure illness with a rash and abdominal pain. At the

Received June 3, 1966. time of examination, her symptoms and signs had cleared and a retrospective diagnosis of Henoch's purpura was made. She remained well until an uncertain date in 1958 , and next came under observation in December of that year with a story that she was falling behind in her school work and that her hand control and balance were poor. She had begun to walk at 14 months and apart from the fact that her speech was a little babyish and there was a slight lisp, her parents were convinced that she had shown a normal development pattern. She was a cheerful co-operative child. Her speech was slow, but reasonably clear, and the content of her conversation was normal for her age. On neurological examination the only positive findings were some general slowness and clumsiness in all movements, a minor degree of ankle clonus, and some disturbance in conjugate downward deviation of the eyes. Although the neurological signs were slight, it seemed certain that they were due to organic disease and she was admitted to hospital for preliminary investigations. Her skull $x$-ray film was normal. Lumbar puncture showed a normal fluid under normal pressure. All biochemical tests on the urine were within normal limits and the Wassermann reaction was negative.

She was referred to Dr. Neil Gordon of the Royal Manchester Childrens' Hospital for a further opinion. He confirmed the history and the clinical findings and added that he thought that she had a cerebellar type of dysarthria. Upward and downward movements of the eyes were defective, but lateral movement was normal and there was no nystagmus. An EEG showed an excessive amount of high voltage irregular slow wave activity in all areas, which was within the theta range (4-7 cycles per second). The alpha rhythm was poorly formed. On overbreathing there was a marked generalized increase in synchrony. The generalized nature of the abnormalities suggested that they were arising from a disturbance within the deep mid-line structures and were secondarily involving the cortical areas. At this stage, Dr. Gordon was also convinced that there was organic disease but was unable to state the nature of the pathology.

The progress of her symptoms was slow. In June 1959, Dr. Gordon thought that her condition was static, but her parents thought there had been some slight improvement. By December, a year after the initial interview, her school reported that she was falling very much further behind. Shortly after this, further clinical deterioration became apparent and she was admitted to the Royal Manchester 


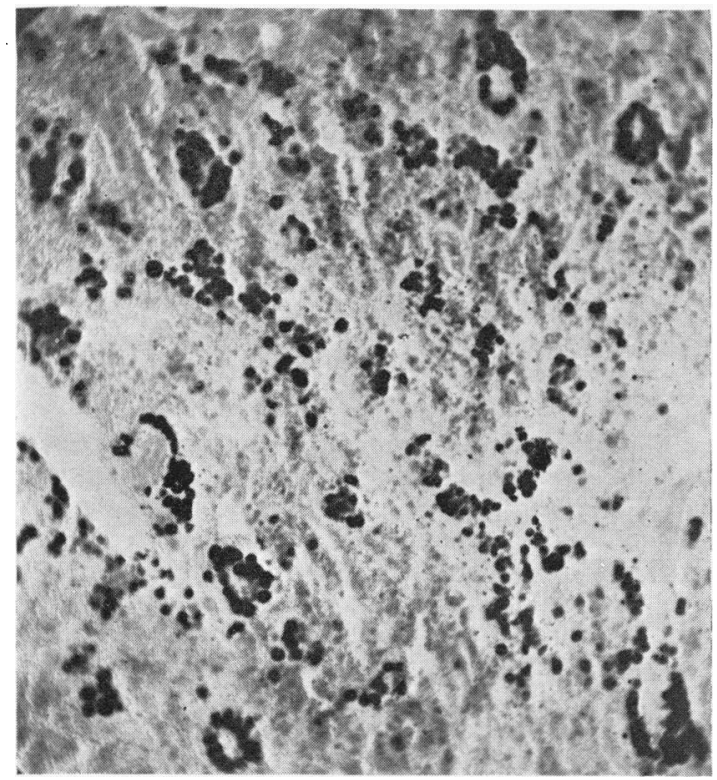

FIG. 1.-Spleen. Macrophages containing haematoxyphil lipid. (Kultschitsky-Pal. $\times$ 55. (48 hours mordant))

Childrens' Hospital. Again her CSF was normal, and air studies did not show any abnormalities of the ventricular system.

In July 1960, she was readmitted to the Royal Manchester Childrens' Hospital for further investigations which failed to establish a diagnosis.

By September the slow deterioration of her nervous system had so far advanced that she was unable to keep her place in normal school at any level and a home teacher was supplied. Although no formal intelligence tests were applied there did not seem to be any intellectual impairment and it appeared to be the incoordination and dysarthria that were holding her back. In April 1961, she was referred to Dr. Sandifer at Great Ormond Street where she was again fully investigated. Dr. Sandifer thought that she had a progressive cerebro-cerebellar degeneration, but was unable to give an exact diagnosis.

By November she was unable to walk, her speech was almost non-existent and she was beginning to have difficulty in swallowing. In December she had a major epileptic fit. This was the first convulsive episode that had been reported at any time in her illness. The EEG now showed that there had been a considerable deterioration. The abnormalities were still generalized, but much more marked than on the previous occasion. She was put on phenytoin sodium (Epanutin), but she continued to have some minor convulsions; the dose was increased and primidone (Mysoline) was added, and the convulsions were then brought under control.

By September 1962, she was confined to bed, and her swallowing eventually became so difficult that she had to be tube-fed. A cerebral biopsy made at this time showed evidence of a lipid storage disease (Dr. Marsden).
Her final admission to hospital was in April 1964. Her nutrition was remarkably good thanks to her mother's care, but she was almost completely immobile and it was very difficult to make out whether her intellect was impaired or not. She continued to deteriorate slowly and died on February 1, 1965, aged 13 years 1 month.

From the time this patient came under medical care until her death, 6 years 2 months had elapsed, and it is probable that the duration of symptoms was something in the region of 7 years.

Necropsy. The body was that of a very thin, otherwise normally-built girl, $129 \mathrm{~cm}$. in height, who showed extreme plantar flexion of the feet. The only naked eye abnormalities were the rather small brain which weighed $1000 \mathrm{~g}$. and an enlarged spleen which weighed $180 \mathrm{~g}$. and showed mild mottling on the cut surface. The liver weighed $1200 \mathrm{~g}$. and was of normal appearance.

Microscopically the liver, kidneys, adrenals, and thymus were unremarkable and contained no foam cells or parenchymal vacuoles. The spleen contained numerous lipid-laden macrophages which were dispersed in small clusters throughout the tissue (Fig. 1). The following staining reactions were obtained in these cells in frozen sections: Baker's method or Kultschitsky-Pal after 48 hours mordanting-black; Luxol fast blue-deep blue; Sudan IV-bright orange; Sudan black-blue-black; PAS-deep crimson; Nile blue-blue; Feyrter-pink. The lipid proved to be partially soluble after a short time in $70 \%$ ethyl alcohol and a much better staining with sudan dyes was obtained after dichromate mordanting.

Neuropathology. Macroscopically, the cerebral hemispheres appeared normal except for slight dilatation of the ventricles. The cerebellum showed marked shrinkage of the gyri and an increased toughness of the tissues indicative of gliosis.

Microscopically, in most parts of the cerebral cortex there were numerous swollen nerve cells typical of lipidosis and resembling in size those seen in juvenile amaurotic idiocy. Neurones with axonal swellings, many times larger than the cell body, were also commonly seen. These changes were not ubiquitous and in many areas the obviously lipidotic cells were interspersed with cells which appeared normal or only showed minimal or equivocal abnormality (Fig. 2). In a section of the occipital lobe and in parts of the temporal cortex the great majority of the cells appeared to be unaffected. There was no proliferation of astrocytes or microglia. A severe loss of nerve cells was only found in the uncus and in the outer layers of the hippocampal gyrus.

Cerebral white matter. There was a mild diffuse fibrous gliosis with focal accentuation in some of the gyral cores. Myelination in both celloidin and frozen sections was within normal limits. Small groups of sudanophil fat granule cells were frequently seen in the perivascular spaces, and in the genu of the corpus callosum there were more substantial lipid deposits in the form of sudanophil droplets in microglial cells and free in the tissue. 


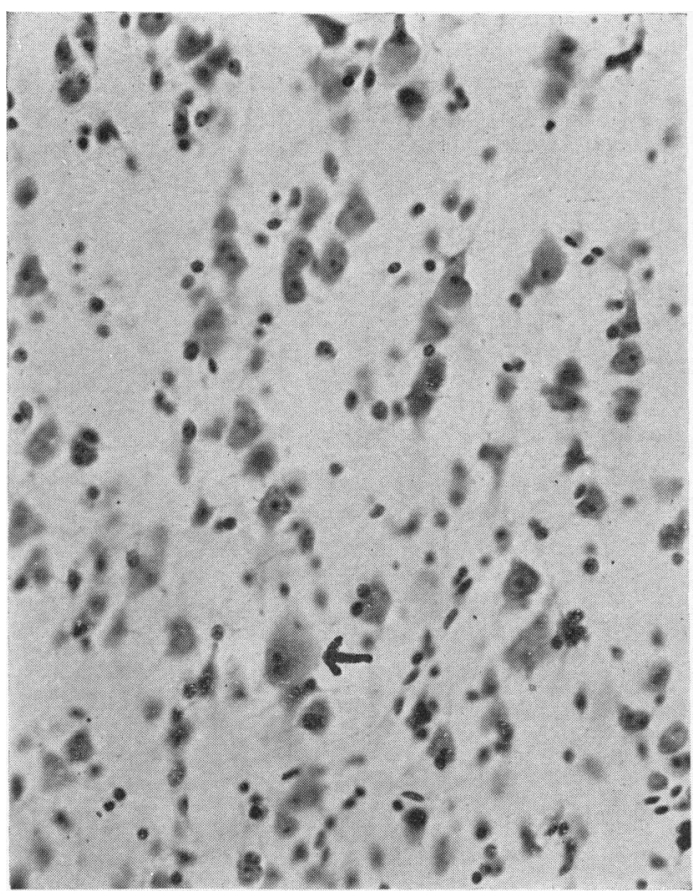

FIG. 2.-Cerebral cortex (temporal lobe). The majority of the nerve cells show little or no lipidosis. The arrow marks a large, swollen nerve cell. (Carbol azure. $\times 266$.

Basal ganglia. The nerve cells of the globus pallidus were greatly swollen (Fig. 3). In the corpus striatum only the large neurones appeared to be affected and in the thalamus there was considerable variation in the intensity of the neuronal lipidosis. Myelination was normal and

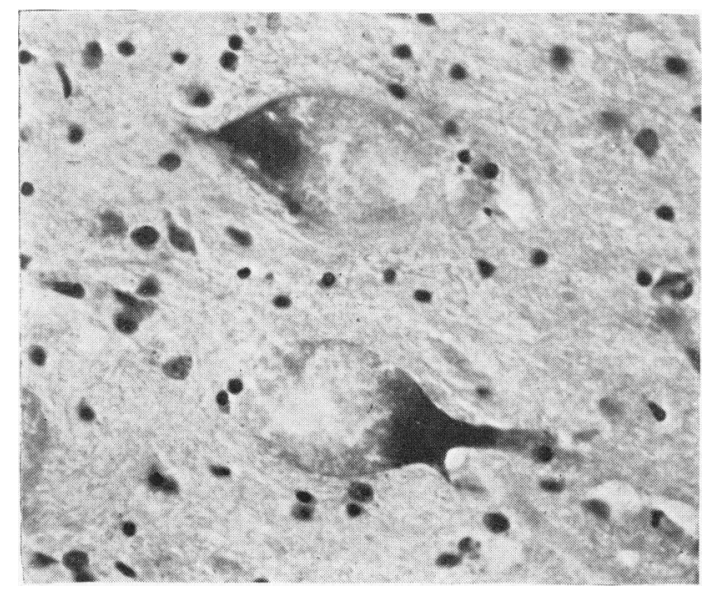

Fig. 3.-Globus pallidus. Nerve cells showing marked lipidosis. (Carbol azure. $\times 150$.

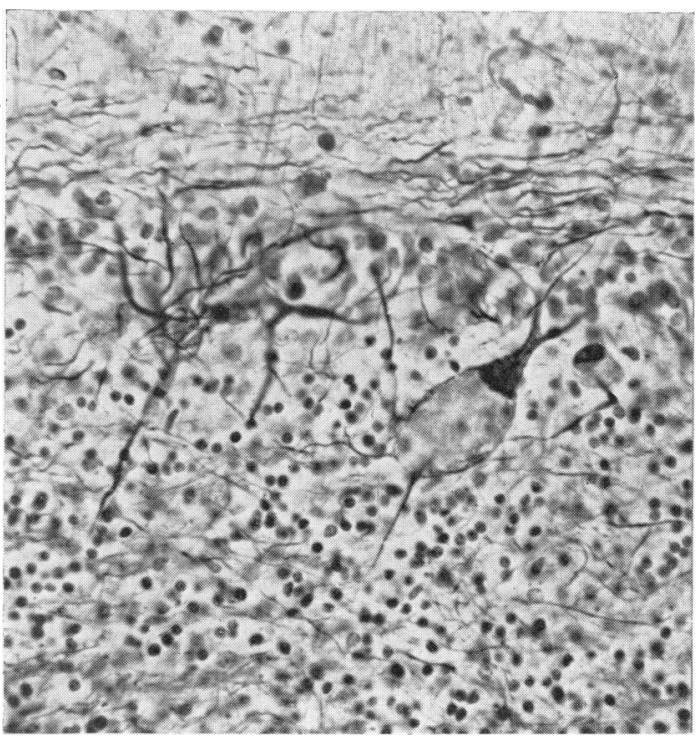

FIG. 4.-Cerebellum. Purkinje cell showing lipidosis. The granular layer is severely depleted. (Bielschowsky. $\times$ 308.)

proliferation of fibrous astrocytes was only present in the thalamus.

Cerebellum. A diffuse and extremely severe cortical atrophy affected both the granular and Purkinje cell layers. Most of the surviving Purkinje cells and the Golgi cells of the granular layer showed marked distension with lipid (Fig. 4). Antler-like swelling of the Purkinje dendrites was occasionally seen, but these probably contained no lipid and were similar to those commonly found in purely degenerative conditions (Fig. 5). These changes were accompanied by a dense fibrous gliosis (Fig. 6). The tangential and basket fibres were preserved, the latter often showing hypertrophy (Fig. 7). There was no microgliosis. The white matter was normally myelinated except for a thinning of fibres in the granular layer and in the dentate nucleus, the cells of the latter being largely preserved though swollen. Fibrous gliosis was particularly intense around the dentate nucleus.

Brain-stem. Lipidosis of nerve cells was widespread. No retrograde degeneration had occurred in the inferior olives but there was a dense fibrous gliosis and a marked proliferation of microglia cells.

Meninges, ependyma, choroid plexus, and blood vessels were unremarkable.

Staining reactions of intracellular lipid. Only the larger, swollen, cells appeared to contain stainable lipid. This was PAS positive, but in other respects there were marked differences from the findings in the splenic foam cells. Sudan stains gave only very feeble coloration even 


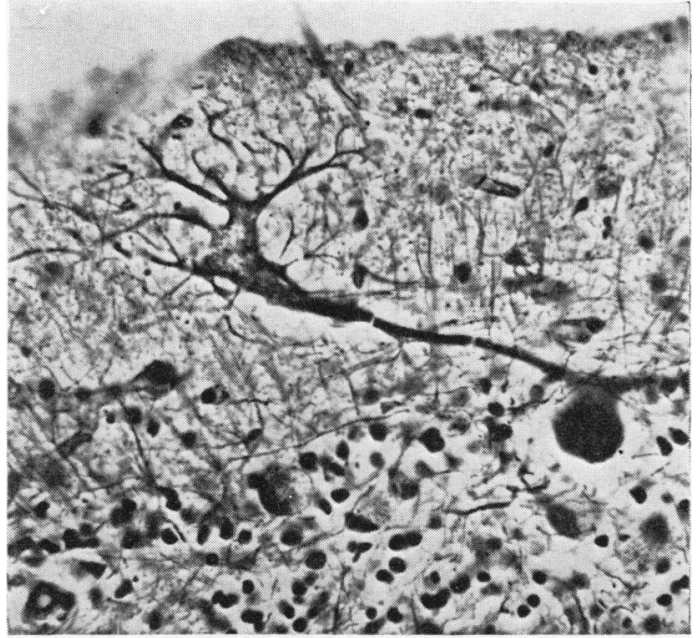

FIG. 5.-Purkinje cell with antler-like swelling of dendrite. (Bielschowsky. $\times$ 308.)

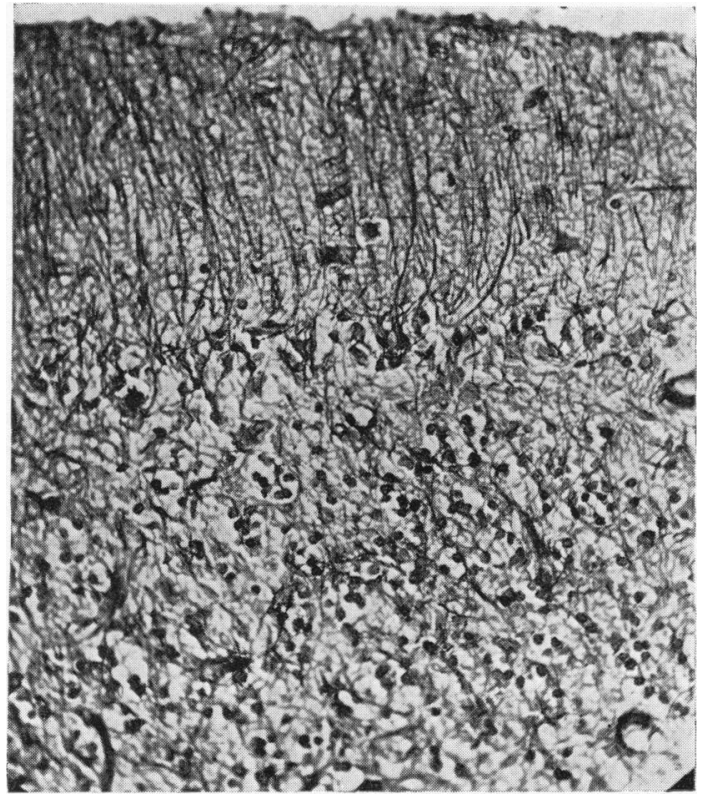

FIG. 6.-Fibrous gliosis in cerebellar cortex. (Holzer. $\times 225$.)

after mordanting. The lipid stained a pale grey, not black, with haematoxylin after 48 hours in mordant (Fig. 8), but the colour intensified after 72 hours in mordant. Only a pale blue was obtained with Luxolfast blue.

\section{Chemistry}

The technical methods were those described in former papers (Tingey and Edgar, 1963). Comparison of the

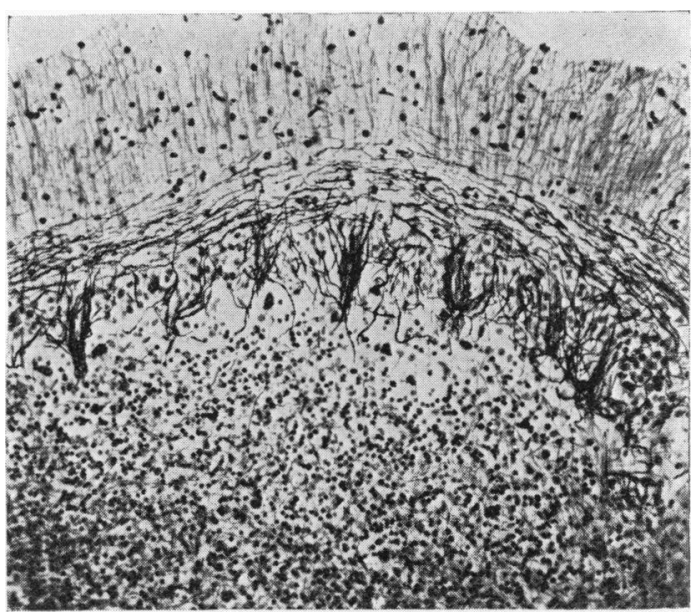

FIG. 7.-Cerebellar cortex showing empty basket fibres. (Cajal's silver nitrate-pyridine method. $\times 130$.

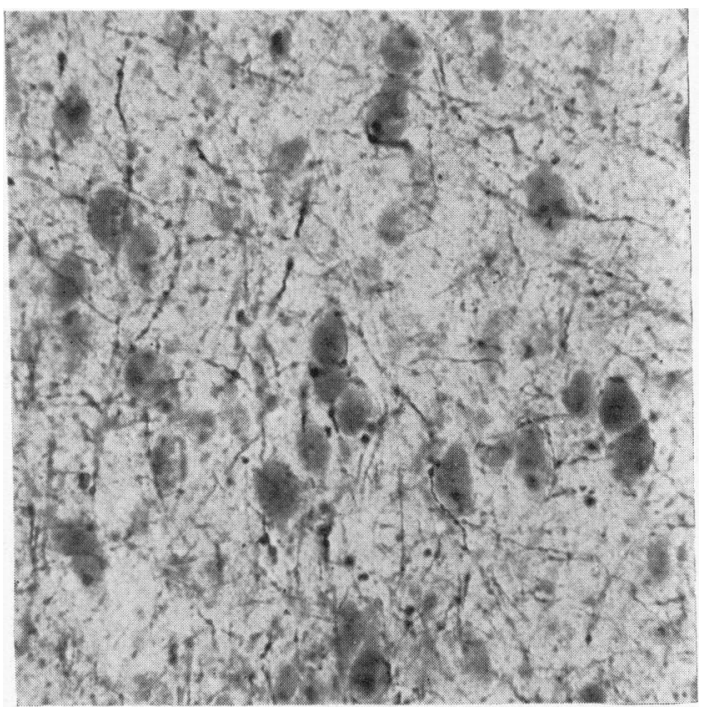

Fig. 8.-Frontal cortex. Nerve cells containing lipid. (Kultschitsky-Pal. $\times 225 .(48$ hours mordant))

chemical findings in brain, spleen, and liver have been made with those in the normal adult and in the case of infantile Niemann-Pick disease previously reported from this laboratory (Norman, Urich, Tingey, and Goodbody, 1958) (Table). The brain and spleen had not been fixed in formalin at the time of analysis. It will be seen that sphingomyelin was increased over normal in spleen and liver; that cholesterol was increased in cerebral cortex and spleen, and that lecithin was increased in cerebral 
TABLE

Comparison of Chemical Findings in Brain, Spleen, and Liver, in a Normal Adult, this Case, and a Case of Infantile Niemann-Pick Disease

\begin{tabular}{|c|c|c|c|c|c|c|c|c|c|c|c|c|}
\hline & \multicolumn{3}{|c|}{ Cerebral Cortex } & \multicolumn{3}{|c|}{ Cerebral White Matter } & \multicolumn{3}{|c|}{ Spleen } & \multicolumn{3}{|c|}{ Liver } \\
\hline & $\begin{array}{c}\text { Normal } \\
\text { Adult }\end{array}$ & $\begin{array}{l}\text { Case } \\
\text { K.C. }\end{array}$ & $\begin{array}{l}\text { Case of } \\
\text { Infant- } \\
\text { ile Nie- } \\
\text { mann- } \\
\text { Pick }\end{array}$ & $\begin{array}{c}\text { Normal } \\
\text { Adult }\end{array}$ & $\begin{array}{l}\text { Case } \\
\text { K.C. }\end{array}$ & $\begin{array}{l}\text { Case of } \\
\text { Infant- } \\
\text { ile Nie- } \\
\text { mann- } \\
\text { Pick }\end{array}$ & $\begin{array}{l}\text { Normal } \\
\text { Adult }\end{array}$ & $\begin{array}{l}\text { Case } \\
\text { K.C. }\end{array}$ & $\begin{array}{l}\text { Case of } \\
\text { Infant- } \\
\text { ile Nie- } \\
\text { mann- } \\
\text { Pick }\end{array}$ & $\begin{array}{c}\text { Normal } \\
\text { Adult }\end{array}$ & $\begin{array}{l}\text { Case } \\
\text { K.C. }\end{array}$ & $\begin{array}{l}\text { Case of } \\
\text { Infant- } \\
\text { ile Nie- } \\
\text { mann- } \\
\text { Pick }\end{array}$ \\
\hline 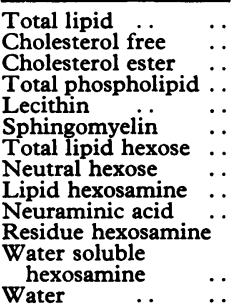 & $\begin{array}{l}37 \cdot 0 \\
5 \cdot 8 \\
\mathrm{Nil} \\
18 \cdot 5 \\
6 \cdot 0 \\
2 \cdot 1 \\
1 \cdot 06 \\
0 \cdot 40 \\
0 \cdot 146 \\
0 \cdot 409 \\
0 \cdot 485 \\
0 \cdot 049 \\
84 \cdot 7\end{array}$ & $\begin{array}{l}36 \cdot 4 \\
6 \cdot 5 \\
0 \cdot 1 \\
21 \cdot 0 \\
9 \cdot 6 \\
1 \cdot 7 \\
1 \cdot 00 \\
0 \cdot 63 \\
0 \cdot 162 \\
0 \cdot 310 \\
0 \cdot 698 \\
0 \cdot 077 \\
84 \cdot 3\end{array}$ & $\begin{array}{l}40 \cdot 6 \\
7 \cdot 5 \\
0 \cdot 5 \\
22 \cdot 7 \\
8 \cdot 3 \\
5 \cdot 6 \\
1 \cdot 37 \\
0 \cdot 38 \\
0 \cdot 238 \\
0 \cdot 482 \\
0 \cdot 462 \\
-7 \\
81 \cdot 4\end{array}$ & $\begin{array}{l}62 \cdot 0 \\
14 \cdot 0 \\
\text { Nil } \\
22 \cdot 9 \\
6 \cdot 3 \\
2 \cdot 6 \\
3 \cdot 72 \\
2 \cdot 00 \\
0 \cdot 045 \\
0 \cdot 058 \\
0 \cdot 195 \\
0 \cdot 020 \\
71 \cdot 6\end{array}$ & $\begin{array}{l}55 \cdot 4 \\
12 \cdot 5 \\
\mathrm{Nil} \\
19 \cdot 6 \\
8 \cdot 7 \\
4 \cdot 0 \\
1 \cdot 82 \\
1 \cdot 03 \\
0 \cdot 092 \\
0 \cdot 089 \\
0 \cdot 324 \\
0 \cdot 062 \\
76 \cdot 6\end{array}$ & $\begin{array}{l}31 \cdot 6 \\
7 \cdot 6 \\
0 \cdot 1 \\
22 \cdot 8 \\
9 \cdot 8 \\
2 \cdot 8 \\
3 \cdot 07 \\
0 \cdot 41 \\
0 \cdot 133 \\
0 \cdot 296 \\
0 \cdot 437 \\
\\
81 \cdot 7\end{array}$ & $\begin{array}{l}30 \cdot 8 \\
1 \cdot 0 \\
0 \cdot 1 \\
4 \cdot 2 \\
3 \cdot 0 \\
0 \cdot 4 \\
0 \cdot 41 \\
0 \cdot 16 \\
0 \cdot 086 \\
0 \cdot 374 \\
0 \cdot 110 \\
77 \cdot 3\end{array}$ & $\begin{array}{c}36 \cdot 4 \\
4 \cdot 8 \\
\mathrm{Nil} \\
10 \cdot 2 \\
4 \cdot 5 \\
6 \cdot 7 \\
0 \cdot 51 \\
0 \cdot 21 \\
0 \cdot 078 \\
- \\
0 \cdot 582 \\
0 \cdot 140 \\
74 \cdot 4\end{array}$ & $\begin{array}{c}49 \cdot 5 \\
6 \cdot 2 \\
0 \cdot 4 \\
29 \cdot 0 \\
5 \cdot 7 \\
13 \cdot 2 \\
0 \cdot 31 \\
0 \cdot 17 \\
0 \cdot 026 \\
0 \cdot 314 \\
73 \cdot 1\end{array}$ & $\begin{array}{l}19 \cdot 3 \\
2.2 \\
0.3 \\
6.4 \\
3.6 \\
0.8 \\
0.33 \\
0.05 \\
0.074 \\
0.272\end{array}$ & $\begin{array}{c}25 \cdot 9 \\
1 \cdot 2 \\
0 \cdot 4 \\
12 \cdot 8 \\
10 \cdot 1 \\
3 \cdot 1 \\
0 \cdot 28 \\
0 \cdot 11 \\
\text { Trace } \\
0 \cdot 460 \\
0 \cdot 029 \\
75 \cdot 2\end{array}$ & $\begin{array}{c}44 \cdot 3 \\
6 \cdot 5 \\
\mathrm{Nil} \\
30 \cdot 2 \\
3 \cdot 0 \\
12 \cdot 4 \\
0 \cdot 75 \\
0 \cdot 15 \\
\mathrm{Nil} \\
\overline{0} \cdot \mathbf{3 4 5} \\
-\overline{77 \cdot 8}\end{array}$ \\
\hline
\end{tabular}

Note: All values except water in $\mathrm{g} . / 100 \mathrm{~g}$. dry tissue.

cortex, spleen, and liver. With the exception of the liver, these changes were in the same direction, but less marked, as those in the infantile case, though there was more neutral hexose (cerebroside) in the cortex and spleen of K.C. than in the infantile case. Thin-layer chromatography confirmed that lecithin was increased in the spleen, liver, and cerebral cortex, and that sphingomyelin was increased in the spleen and liver. The low figure obtained on fresh material for the cortical sphingomyelin of K.C. was not confirmed by thin-layer chromatography, which showed a well-marked excess in the C18 fraction (Pilz and Jatzkewitz, 1964), but not so much as in the infantile case. We cannot explain this discrepancy except by suggesting that the samples of tissue may have come from parts of the cerebral cortex differing in the number of storage cells. The higher level of myelin lipids in the white matter of K.C. compared with the infantile case reflects the considerably better myelination seen histologically.

\section{Discussion}

The clinical diagnosis of lipidosis in this patient was made after a cerebral biopsy had been performed in the terminal stages of the illness. The absence of hepatosplenomegaly had seemed to rule out Niemann-Pick disease. The normal vision, the apparently mild mental deterioration, and the late onset of epilepsy had been inconsistent with the diagnosis of juvenile amaurotic idiocy, which the predominant cerebellar ataxia might otherwise have suggested. The chemical findings in this case corresponded closely with those reported recently from this laboratory in two other examples of this form of lipidosis (Norman, Tingey, and Fowler, 1965; Norman, Oppenheimer, Tingey, and Aherne, 1966). In all three patients, the spleen showed similar histological and histochemical features to those found in the infantile form, though the extent of the foam cell infiltration was less. Chemically, there was the characteristic increase in cholesterol and sphingomyelin, though the latter was not so high as in the infantile form. There is little doubt that if the condition is suspected clinically, the organ of choice for biopsy is the spleen, for unless there are foam cells containing lipid which is intensely haematoxyphil after chromation and easily soluble in alcohol, the diagnosis of Niemann-Pick disease in any age-group should not be made. These cases evidently belong to what Crocker and Farber called the 'lower-tissue-lipid' variant of the disease. For this reason, we have retained the name of 'Niemann-Pick disease' to describe this condition, while realizing that it is doubtless a distinct genetic entity and that future research may be expected to split this group of phospholipidoses into more precisely defined component parts.

The histochemical reactions in the brain gave little indication of the nature of the stored lipids but have been included because they may be of help in diagnostic cerebral biopsies, since they are similar to those obtained in our previous juvenile cases. The difficulties in interpreting histochemical findings in lipid mixtures have been emphasized by Stam, Deierkauf, and Heslinga (1962), and there can be little doubt that chemical analysis and chromatography are the methods of choice.

Perhaps the most remarkable finding in this case was the chemical evidence of lipid storage in the liver, despite its normal histology. In the infantile form there is obvious histological evidence of 
lipidosis, not only in the foam cells but also in the vacuolated parenchyma, and it might well be assumed that this lipid is the visible expression of the large excess of sphingomyelin found chemically. In our case, it must be postulated that the lipid storage had occurred in invisible form, and this view is supported by an observation made in the second of our previous cases (Norman et al., 1966) in which the histologically unremarkable kidney also showed unequivocal chemical evidence of lipid storage.

The very severe cerebellar atrophy found in our case has not, to our knowledge, been reported previously in Niemann-Pick disease, either in the infantile or in the older age-groups. Indeed, in both our previous juvenile cases the Purkinje cells showed little or no lipidosis, and the same finding has been recorded in Case 12 of the Crocker and Farber series and also in the juvenile case briefly reported by Ford (1960). We had previously thought that the virtual exemption of the cerebellum from lipidosis or severe atrophy was a characteristic of this juvenile variant. However, it is now clear that cerebellar atrophy may be an important cerebral lesion, and that the clinical picture may be dominated by its effects. Similar regional variation in the intensity of lesions is well known in the group of amaurotic idiocies, but Niemann-Pick disease is a much rarer condition, and the range of possible histological and chemical variations has only become apparent in recent years.

We have retained the name 'Niemann-Pick' to identify this condition, though there are obvious differences from the well-established infantile form. No doubt the use of an eponym should be restricted to a clinical syndrome or specific disease, but until more of the juvenile variants have been adequately examined it seems inadvisable to complicate the present nomenclature. Eventually this complex group of phospholipidoses will be broken down into its constituent members and a more precise classification will then be possible.

\section{Summary}

A girl aged 13 years at death had developed a slowly progressive neurological illness which had begun when she was 6 years old. The main signs were those of cerebellar disease. Vision was unimpaired and intellectual deterioration was not a marked feature. Epilepsy occurred late in the illness. There was no clinical evidence of visceral involvement. Cerebral biopsy revealed lipid storage in the nerve cells. At necropsy the spleen was enlarged to $180 \mathrm{~g}$., and microscopically contained foam cells of Niemann-Pick type containing strongly haematoxyphil and easily soluble lipid. Chemically, the spleen showed an increased content of sphingomyelin and cholesterol. The liver, which was histologically unremarkable, showed increased lecithin and sphingomyelin. In the brain there was widespread swelling of the nerve cells with storage of lipid material which stained very feebly with haematoxylin. The cerebral cortex was less diffusely affected than other parts of the brain and contained large numbers of apparently normal nerve cells. Chemically, there was an increase of sphingomyelin, lecithin, and cholesterol. In the cerebellum there was severe cortical atrophy with substantial loss of granule and Purkinje cells. The changes in this case have been compared with those in the infantile form of Niemann-Pick disease and with other previously recorded examples of the juvenile variant.

We are grateful to Dr. N. Gordon for his clinical and EEG reports, to Dr. F. Hillman for the necropsy findings, and to Dr. B. Marsden for his report on the cerebral biopsy.

\section{REFERENCES}

Crocker, A. C. (1961). The cerebral defect in Tay-Sachs disease and Niemann-Pick disease. $\mathcal{F}$. Neurochem., 7, 69.

-, and Farber, S. (1958). Niemann-Pick's disease: a review of 18 patients. Medicine (Baltimore), 37, 1.

Ford, F. R. (1960). Diseases of the Nervous System in Infancy, Childhood and Adolescence, 4th ed., p. 823. Thomas, Springfield, Illinois.

Norman, R. M., Oppenheimer, D. R., Tingey, A. H., and Aherne, W. A. (1966). Histological and chemical findings in juvenile Niemann-Pick's disease. f. neurol. Sci. In the press.

, Tingey, A. H., and Fowler, M. C. (1965). The subacute form of Niemann-Pick's disease. Proc. 5th int. Congr. Neuropath., Zurich, pp. 143-148.

_, Urich, H., Tingey, A. H., and Goodbody, R. A. (1959) Tay-Sachs' disease with visceral involvement and its relationship to Niemann-Pick's disease. F. Path. Bact., 78, 409.

Pilz, H., and Jatzkewitz, H. (1964). Dünnschichtchromatographische Bestimmungen von $\mathrm{C}^{18}$ - und $\mathrm{C}^{24}$-Sphingomyelin in normalen und pathologischen Gehirnen einschliesslich eines Falles von Niemann-Pick'-scher Erkrankung. F. Neurochem., 11, 603.

Tingey, A. H., and Edgar, G. W. F. (1963). A contribution to the chemistry of the leucodystrophies. ibid., 10, 817.

Stam, F. C., Deierkauf, F. A., and Heslinga, F. J. M. (1962). Histochemical and chromatographic study of the normal myelin sheath. Psychiat. Neurol. Neurochir. (Amst.), 65, 242. 